\title{
Ordinary kriging vs inverse distance weighting: spatial interpolation of the sessile community of Madagascar reef, Gulf of Mexico
}

\author{
Salvador Zarco-Perello ${ }^{\text {Corresp., }}{ }^{1,2}$, Nuno Simões ${ }^{1}$ \\ 1 Unidad Académica Sisal, Facultad de Ciencias, Universidad Nacional Autónoma de México, Sisal, Yucatan, Mexico \\ 2 School of Biological Sciences and UWA Oceans Institute, University of Western Australia, Perth, Western Australia, Australia \\ Corresponding Author: Salvador Zarco-Perello \\ Email address: salvador.zarco.perello@gmail.com
}

Information about the distribution and abundance of the habitat-forming sessile organisms in marine ecosystems is of great importance for conservation and natural resource managers. Spatial interpolation methodologies can be useful to generate this information from in situ sampling points, especially in circumstances where remote sensing methodologies cannot be applied due to small-scale spatial variability of the natural communities and low light penetration in the water column. Interpolation methods are widely used in environmental sciences; however, published studies using these methodologies in coral reef science are scarce. We compared the accuracy of the two most commonly used interpolation methods in all disciplines, inverse distance weighting (IDW) and ordinary kriging (OK), to predict the distribution and abundance of hard corals, octocorals, macroalgae, sponges and zoantharians and identify hotspots of these habitatforming organisms using data sampled at three different spatial scales $(5,10$ and $20 \mathrm{~m})$ in Madagascar reef, Gulf of Mexico. The deeper sandy environments of the leeward and windward regions of Madagascar reef were dominated by macroalgae and seconded by octocorals. However, the shallow rocky environments of the reef crest had the highest richness of habitat-forming groups of organisms; here, we registered high abundances of octocorals and macroalgae, with sponges, Millepora alcicornis and zoantharians dominating in some patches, creating high levels of habitat heterogeneity. IDW and OK generated similar maps of distribution for all the taxa; however, cross-validation tests showed that IDW outperformed OK in the prediction of their abundances. When the sampling distance was at $20 \mathrm{~m}$, both interpolation techniques performed poorly, but as the sampling was done at shorter distances prediction accuracies increased, especially for IDW. OK had higher mean prediction errors and failed to correctly interpolate the highest abundance values measured in situ, except for macroalgae, whereas IDW had lower mean prediction errors and high correlations between predicted and measured values in all 
cases when sampling was every $5 \mathrm{~m}$. The accurate spatial interpolations created using IDW allowed us to see the spatial variability of each taxa at a biological and spatial resolution that remote sensing would not have been able to produce. Our study sets the basis for further research projects and conservation management in Madagascar reef and encourages similar studies in the region and other parts of the world where remote sensing technologies are not suitable for use. 
1 Ordinary kriging vs inverse distance weighting: spatial interpolation of the sessile community of Madagascar reef, Gulf of Mexico.

\section{ABSTRACT}

Information about the distribution and abundance of the habitat-forming sessile organisms in marine ecosystems is of great importance for conservation and natural resource managers. Spatial interpolation methodologies can be useful to generate this information from in situ sampling points, especially in circumstances where remote sensing methodologies cannot be applied due to small-scale spatial variability of the natural communities and low light penetration in the water column. Interpolation methods are widely used in environmental sciences; however, published studies using these methodologies in coral reef science are scarce. We compared the accuracy of the two most commonly used interpolation methods in all disciplines, inverse distance weighting (IDW) and ordinary kriging (OK), to predict the distribution and abundance of hard corals, octocorals, macroalgae, sponges and zoantharians and identify hotspots of these habitat-forming organisms using data sampled at three different spatial scales $(5,10$ and $20 \mathrm{~m})$ in Madagascar reef, Gulf of Mexico. The deeper sandy environments of the leeward and windward regions of Madagascar reef were dominated by macroalgae and seconded by octocorals. However, the shallow rocky environments of the reef crest had the highest richness of habitatforming groups of organisms; here, we registered high abundances of octocorals and macroalgae, with sponges, Millepora alcicornis and zoantharians dominating in some patches, creating high levels of habitat heterogeneity. IDW and OK generated similar maps of distribution for all the 
taxa; however, cross-validation tests showed that IDW outperformed OK in the prediction of their abundances. When the sampling distance was at $20 \mathrm{~m}$, both interpolation techniques performed poorly, but as the sampling was done at shorter distances prediction accuracies increased, especially for IDW. OK had higher mean prediction errors and failed to correctly interpolate the highest abundance values measured in situ, except for macroalgae, whereas IDW had lower mean prediction errors and high correlations between predicted and measured values in all cases when sampling was every $5 \mathrm{~m}$. The accurate spatial interpolations created using IDW allowed us to see the spatial variability of each taxa at a biological and spatial resolution that remote sensing would not have been able to produce. Our study sets the basis for further research projects and conservation management in Madagascar reef and encourages similar studies in the region and other parts of the world where remote sensing technologies are not suitable for use.

\section{INTRODUCTION}

Coral reefs are important centres of biodiversity (Plaisance et al., 2011) that provide multiple natural resources and ecosystem services to human societies (Mumby et al., 2011). However, multiple disturbances are impacting these ecosystems and causing changes in their community structure (Norström et al., 2009). The main groups of sessile organisms inhabiting coral reefs are hard corals (Scleractinian and millepores), macroalgae, octocorals, sponges, and zoantharians (Lewis, 2006; Diaz \& Rützler, 2001; Norström et al., 2009; Wee et al., 2017); these taxa are habitat-forming organisms (HFO) that shelter many species of fishes, echinoderms, gastropods, mollusks and crustaceans (Duffy 1992, Goh, Ng \& Chou, 1999; Pérez et al., 2005; Santavy et al., 2013; Cházaro-Olivera \& Vázquez-López, 2014), which in turn sustain the fisheries and tourism industries of the world (Moberg \& Folke, 1999). Hard corals used to dominate the seascape of tropical reefs; however, their populations have declined in recent decades due to multiple disturbances such as overfishing, eutrophication and high temperatures (Nystrom \& Folke, 2001), allowing other HFO to increase their abundance (Nyström, Folke \& Moberg, 2000; Wilkinson, 2004; Ruzicka et al., 2013; McMurray, Finelli \& Pawlik, 2015). Many coral reefs are now dominated by macroalgae (McManus \& Polsenberg, 2004), with other reefs presenting high percentages of substrate covered by octocorals, zoantharians and sponges (Norström et al., 2009; Cruz et al., 2014; Bell et al., 2013). Although there is uncertainty in the scientific community 
60 about the specific ecological changes that may take place in the future, it is very likely that 61 changes will continue as global warming intensifies (Bell et al., 2013; Gross, 2013; Ruzicka et al., 2013). Most ecological studies have lacked a community perspective and have focused on just a few taxonomic groups, mainly Scleractinian corals and macroalgae (McManus \& Polsenberg, 2004). However, as the community structure of coral reefs transitions, the need to monitor the distribution and abundance of all HFO has increased (Norström et al., 2009; Bell et al., 2013; Ruzicka et al, 2013; McMurray, Finelli \& Pawlik, 2015).

The assessment of the abundance of all HFO is important per se; however, these data needs to be integrated into geographic information systems (GIS) for scientific, conservation and resource management organizations, since this allows the planning of monitoring programs and establishment of conservation areas (Franklin et al., 2003; Lee et al., 2015). Much research about the spatial distribution of the sessile benthic communities in reef ecosystems has focused on remote sensing (Kachelriess et al., 2014). Remote sensing technologies allow the assessment of the distribution of marine sessile organisms in extensive areas following complex procedures for atmospheric correction and spectral unmixing to achieve valid habitat classifications (Hochberg $\&$ Atkinson, 2003). However, accuracy of remote sensing diminishes as water turbidity and depth increase because of the light absorption by the water column (Lucas \& Goodman, 2014). The ability of remote technologies to identify different taxa and accurately estimate their abundance is limited (Kutser \& Jupp, 2006) and the coarse spatial resolution of the images may not match the natural patchy variation of the sessile communities (Andrefouet et al., 2003; Kachelriess et al., 2014), requiring an in situ verification of the remote sensing estimations (ground-truthing), which ultimately add extra costs and effort to the studies (Botha et al., 2013; Lucas \& Goodman, 2014). By now these procedures are only ideal for macro-scale studies of reefs located in clear and shallow water environments (e.g. Zapata-Ramirez et al., 2014). However, there are many relatively small coral reefs $\left(\right.$ e.g. $\left.\sim 1 \mathrm{~km}^{2}\right)$ in deep or turbid environments which are of conservation priority (Cohen \& Foale, 2013). In these cases, species distributions and abundance estimated through spatial interpolations based entirely on data gathered in situ may be more appropriate, since they do not have depth, water clarity or spatial scale limitations and can be integrated into GIS (McClanahan et al., 2011; Walker et al., 2012; D’Antonio et al., 2016). 
91 There are many spatial interpolation methodologies used to predict the distribution of variables

92 of interest in different disciplines (Li \& Heap, 2008). Among them, kriging, a geostatistical

93

94 95 96 methodology, and inverse distance weighting (IDW), a simpler non-geostatistical methodology, have been used widely to predict many environmental and agricultural variables (reviewed by $\mathrm{Li}$ \& Heap, 2008, 2011, 2014), such as soil fertility (Mueller et al., 2004), mud content (Li et al., 2011) and bathymetry (Bello-Pineda \& Hernández-Stefanoni, 2007). Published studies in marine ecology applying these methods to generate distribution and abundance maps of marine organisms are less common. Kriging has been used for crustaceans (Rufino et al., 2005, Surette, Marcotte \& Wade, 2007), echinoderms (Hernandez-Flores et al., 2015), fish (Rueda \& Defeo 2003, De Mazières \& Comley, 2008; Ruppert et al., 2009), seagrass (Holmes et al., 2007), hard corals and encrusting algae (Knudby et al., 2013); whereas studies using IDW have been limited to mollusks (Berry, Hill \& Walker, 2016), coral cover (Walker et al., 2012; D'Antonio et al., 2016), coral diameters (Burman, Aronson \& Woesik, 2012) and coral and fish diversity (McClanahan et al., 2011). However, no study has applied these two methodologies across different HFO.

The Gulf of Mexico has many important reef systems that have been studied extensively (Chávez, Tunnell \& Withers, 2007; Hickerson et al., 2008; Horta-Puga et al., 2015).

Nonetheless, there exists a dearth of information about many other smaller reefs located on the Yucatan continental shelf and developing in turbid waters, despite being important centres of biodiversity and fishery resources (Zarco-Perello et al. 2013). Our study (i) gathered baseline information of the abundance and community structure of all HFO inhabiting one of these poorly studied reefs and (ii) compared the accuracy of IDW and OK to interpolate their abundances with data sampled at different distances and synthesize this information into a map of HFO richness.

\section{MATERIALS AND METHODS}

Sampling design 
120 From August to October of 2007 we completed 15 photo-transects across the extent of

121 Madagascar reef in the Gulf of Mexico; each transect measured $200 \mathrm{~m}$ in length and was located

$122200 \mathrm{~m}$ from adjacent transects (Zarco-Perello, Moreno-Mendoza \& Simoes, 2014) (Fig. 1).

123 Photo-quadrats $\left(0.8 \mathrm{~m}^{2}\right)$ of the benthos were taken every $5 \mathrm{~m}$ along the transects, each one

124 representing a sampling point $(\mathrm{n}=580)$. We recorded information about geographic coordinates,

125 depth, substrate type (i.e. rock, sand and rubble) and reef region (i.e. windward, crest and

126 leeward) of each sampling point.

127

128 Community structure analyses

129

Relative abundance of all the HFO was estimated as percent cover in each photograph using the point-count method (see Fabricius \& McCorry, 2006 and Ruzicka et al., 2013). Biological similarities between the different regions of the reef were analysed with non-metric MultiDimensional Scaling (nmMDS) and an Analysis of Similarity (ANOSIM) to test for statistical significance; data was log transformed and the distance matrix was calculated with the braycurtis method using the software R v.3.1.3 (vegan package) (The R Foundation) with the interphase RStudio v.0.99.473 (Rstudio, Inc.).

Spatial interpolation analyses

The spatially referenced percent cover data from each photograph was used to interpolate the abundance of each HFO using IDW and Ordinary Kriging (OK), the most recommended univariate method of kriging (Li \& Heap, 2014). IDW and OK interpolations are based on the principle of spatial autocorrelation of samples by distance, where the closer the samples are from each other, the more similar would be their values. Under this principle, the prediction of a value in an unsampled place is calculated by giving more weight to samples that are closer to the prediction point. However, IDW uses arbitrary exponential weighting of the influence that each sample has according to distance, whereas $\mathrm{OK}$ involves a process of variography to model the spatial autocorrelation of the data to assign weights, which can result in better interpolations under an appropriate sampling design; nonetheless it is time consuming and it is still subjective 150 since it involves many user decisions (Li \& Heap, 2014). Finally, both interpolators use a 
151 determined quantity of observations for the predictions; these observations must be located

152 within a 'searching window', an area around the point of prediction, which geometry is defined

153 by the user based on the empirical knowledge of the phenomena under study (Li \& Heap, 2014).

154 The interpolation analyses of OK and IDW were done considering different sampling distances

$155(5,10$ and $20 \mathrm{~m})$ to evaluate the effort required to capture the spatial structure of each HFO.

156 Modelling parameters changed under each sampling distance. For OK, the models (e.g. spherical

157 and exponential) that best fitted the data of the variograms of each HFO were selected; for IDW,

158 different power values (i.e. 1, 2, 3) were used as weighting factors for each HFO. The parameters

159 of the searching window (i.e. length of axis 1 and axis 2) were the same for both methodologies.

160 The best models of OK and IDW for each HFO under each sampling distance were selected

161 following cross-validations (Goovaerts, 1997; Supplementary Information). The performance of

162 each methodology was compared based on the absolute mean error (ME) of their predictions (i.e.

163 based on the absolute values of the errors), the regression coefficient $\left(\mathrm{r}^{2}\right)$ of predicted against

164 measured values, graphical comparisons (box-plots) of the distribution of predicted and

165 measured data and visual examination of the predicted maps (Hernandez-Flores et al., 2015). We

166 completed the interpolation map of hard corals only with data of Millepora alcicornis, Linnaeus,

167 1758, since the inclusion of Scleractinian corals produced overestimations on the predictions

168 given the small colony sizes found in situ $\left(<25 \mathrm{~cm}^{2}\right)$. For such small and scattered colonies, is

169 better to produce point maps representing presence/absence, to avoid the creation of misleading

170 maps.

171 The descriptions of the spatial patterns of all HFO were based on the interpolated abundance

172 maps of the best performing methodology (OK vs. IDW). These interpolated maps were

173 transformed to rasters (5 $\mathrm{m}$ resolution) and reclassified to presence/absence with the same

174 resolution. These rasters were used to create a map of the HFO richness on the reef by summing

175 all the HFO present in each cell ( 0 to 5 scale) using the tool Raster Calculator. All the spatial

176 interpolation analyses were done using the software ArcMap v.10.3 with the Geostatistical and

177 Spatial Analyst extensions (ESRI corp.). See Li \& Heap (2008) for a list of alternative software

178 for interpolation methodologies. 
180

181

182

183

184

185

186

187

188

189

190

191

192

193

194

195

196

197
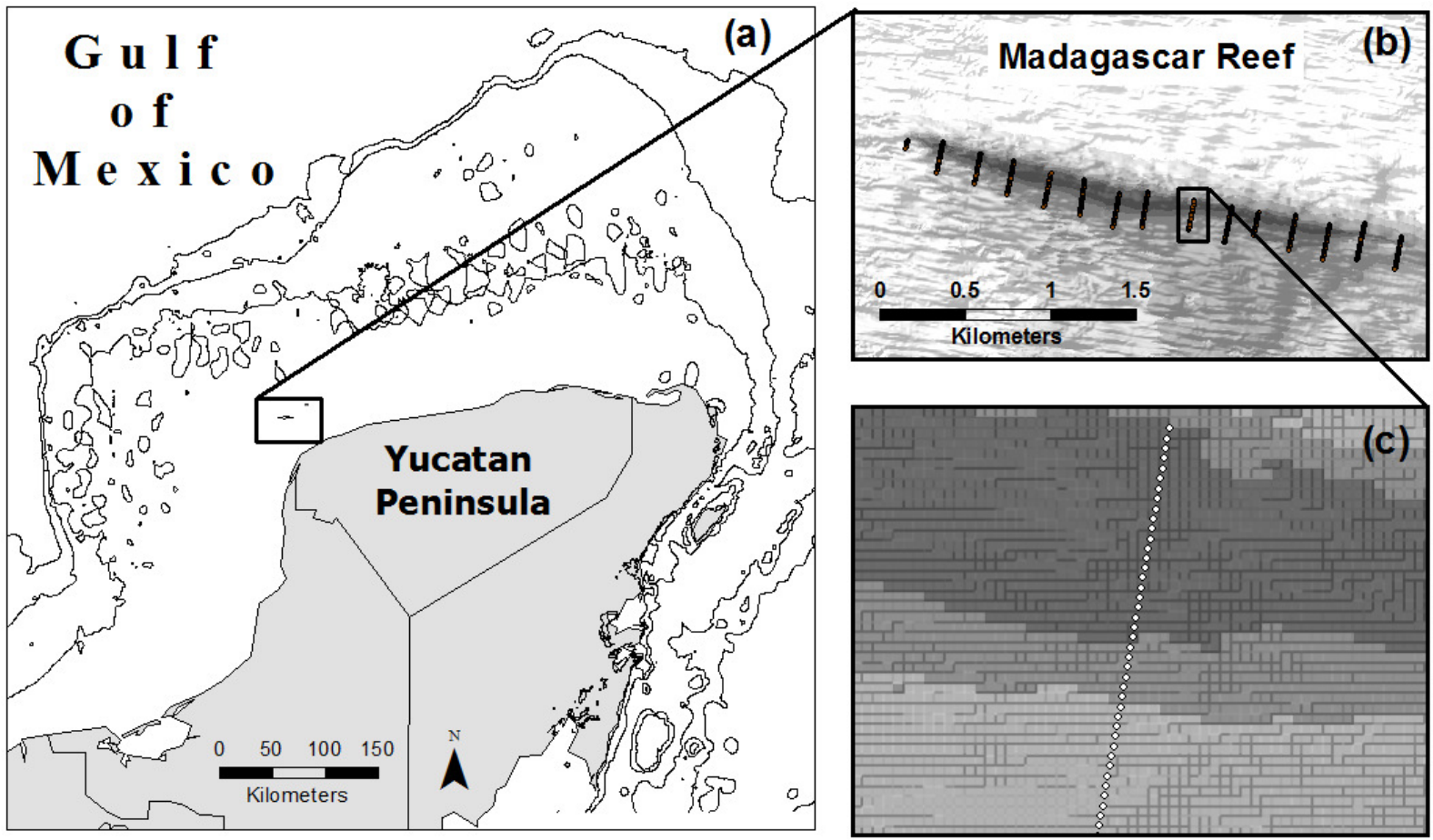

Figure 1. Location of Madagascar reef in the Gulf of Mexico (a) and distribution of sampling points across the bathymetric gradient along the reef $(b, c)$.

\section{RESULTS}

Community Structure

The sessile community of Madagascar reef differentiated spatially between the reef crest and the windward and leeward regions. The nmMDS showed two statistically significant different clusters; one belonging to sampling units from the reef crest and another one belonging to the leeward and windward regions (ANOSIM, p=0.001) (Fig. 2). The reef crest presented all HFO, whereas the windward and leeward regions were greatly dominated by macroalgae, with octocorals in a lower magnitude (Fig. 3).

The reef crest, which is the shallower and rockier region of the reef (depth: $6.8 \pm 1.4 \mathrm{~m}$ ), had the higher average abundances of hard corals (3.7\%), zoantharians (Palythoa spp. and Zoanthus spp.) $(7.7 \%)$ and sponges (7.0\%), with octocorals (44.0\%) and macroalgae $(37.4 \%)$ 
198 dominating the reefscape (Fig. 4). As depth increased towards the windward (depth: $16.2 \pm 2.6$

199

200

201

202

203

204

205

206

207

208

209

210

211

212 $\mathrm{m})$ and leeward regions (depth: $14.8 \pm 0.16 \mathrm{~m}$ ), the percent cover of sandy substrate and macroalgae increased as well, whereas the abundance of all the other sessile groups decreased (Fig. 4). Macroalgae covered $80 \%$ of the substrate in each region, followed by octocorals ( $9 \%$ windward, $14 \%$ leeward) (Fig. 4). Hard corals, sponges and zoantharians were scarce in these environments but had slightly higher abundances at the windward $(2.6 \%, 1.0 \%$ and $0.7 \%$, respectively) than at the leeward region ( $1.4 \%, 0.8 \%$ and $0 \%$, respectively) (Fig. 4).

Scleractinian corals had low abundances in general but were more abundant at the windward and leeward regions $(0.7 \%)$ than at the reef crest $(0.1 \%)$.

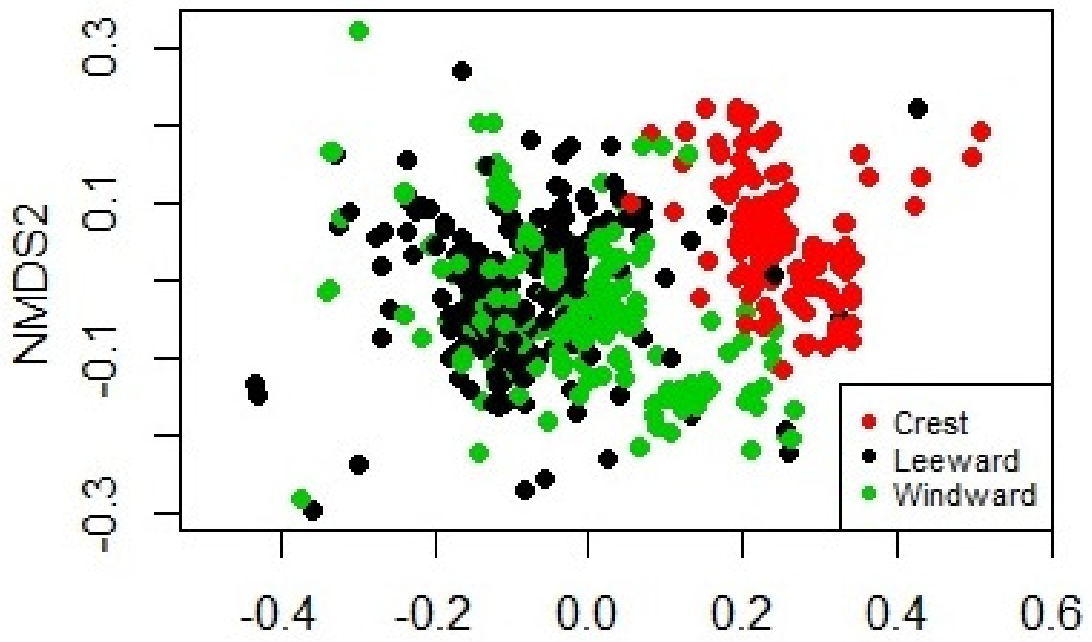

NMDS1

Figure 2. Non-metric Multidimensional Scaling biplot showing the similarity on the biological composition between sampling units taken at the windward, reef crest and leeward zones of Madagascar reef, Gulf of Mexico. 

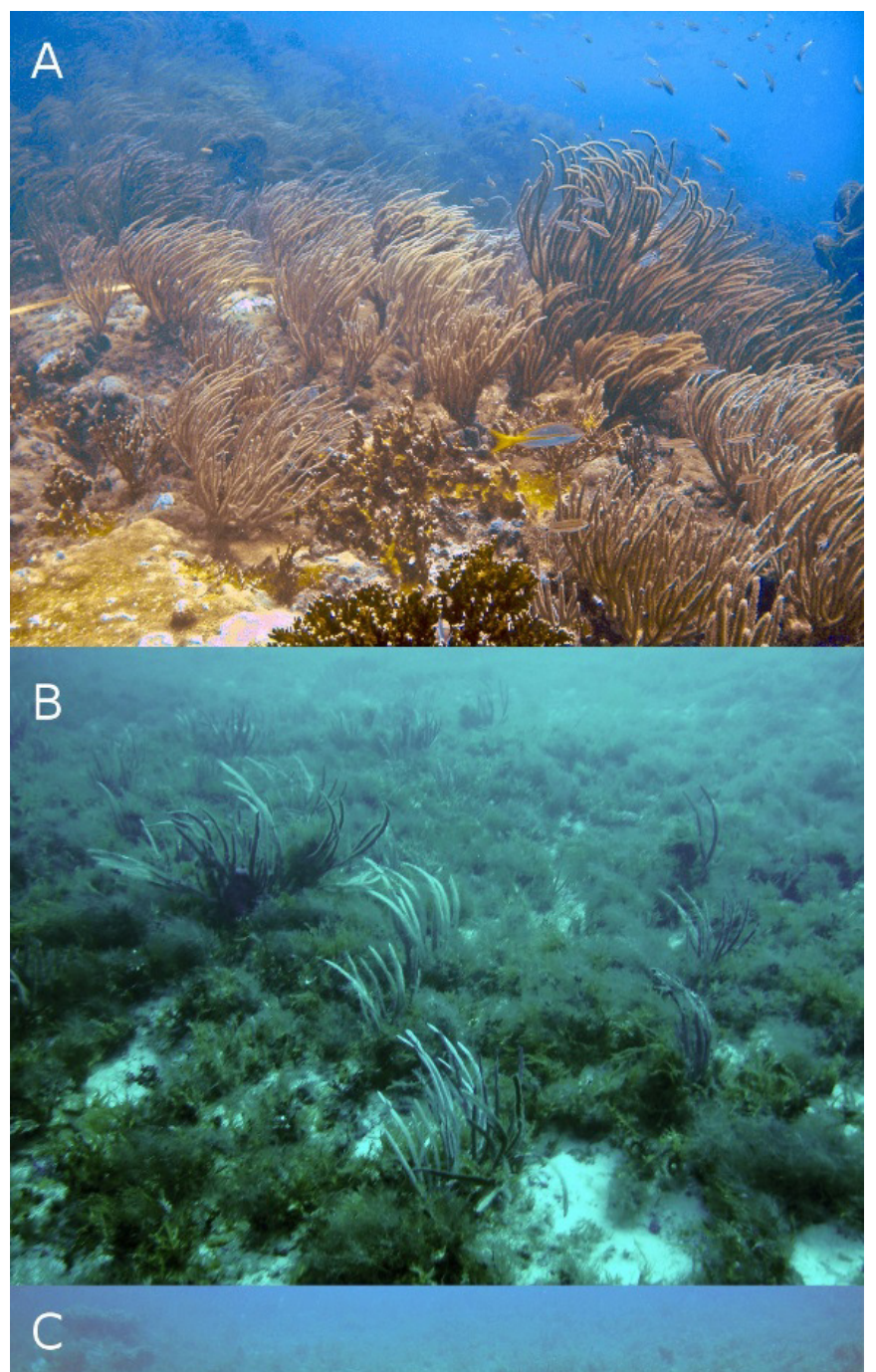

214 Figure 3. Typical reefscapes of Madagascar reef, Gulf of Mexico: The shallow (depth: $6.8 \pm 1.4 \mathrm{~m}$ ) rocky

215 reef crest $(A)$, and the deeper sandy leeward $(14.8 \pm 0.16 \mathrm{~m})(\mathrm{B})$ and windward $(16.2 \pm 2.6 \mathrm{~m})$ (C)

216 regions. 
220

221

222

223

224

225

226

227

228

229

230

231

232

233

234

235

236

237

238

239

240

241
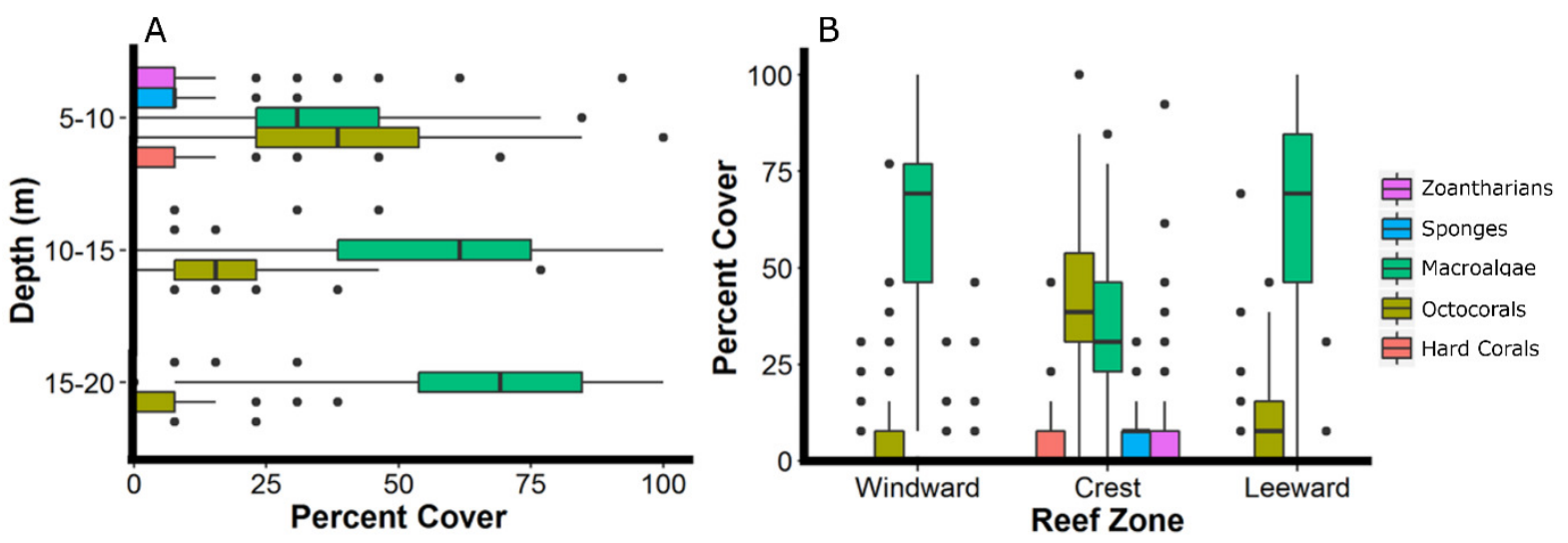

Figure 4. Relative abundance of the main groups of sessile organisms at different depth intervals $(A)$ and zones (B) of Madagascar reef, Gulf of Mexico. Box-plots represent four quartiles and median, with outliers as points.

Spatial interpolations

The interpolation maps generated by both methodologies captured similar patterns of distribution and abundance for each HFO, with no anomalies detected visually. However, cross-validation analyses showed that the accuracy of the predictions changed depending on the sampling distance, the method and the particular HFO being interpolated. In general, we found that as the sampling was done at shorter distances, the predictions of both methodologies had higher accuracies. Mean errors of the interpolations were highest at the longest sampling distance (i.e. $20 \mathrm{~m}$ ) and decreased as the sampling was done at shorter distances. In agreement, the correlation coefficient between measured and predicted values $\left(\mathrm{r}^{2}\right)$ increased as the sampling distance decreased, reaching its maximum when sampling was done every 5 meters (Fig 5). Although this pattern was generally found for both interpolation methodologies, IDW presented lower mean errors and higher $\mathrm{r}^{2}$ values than $\mathrm{OK}$ across all HFO interpolations as the sampling was more frequent (i.e. sampling distances of 10 and $5 \mathrm{~m}$ ); however, interpolations of both methods using data from the longest sampling distance (i.e. $20 \mathrm{~m}$ ) had similar accuracies (Fig 5). This pattern was more consistent considering $\mathrm{r}^{2}$ rather than the mean errors of the predictions which had some contrasting values for some HFO. The interpolations with IDW of macroalgae and zoantharians 
242 had lower mean errors than $\mathrm{OK}$ at all sampling distances, whereas the mean errors of the 243 interpolations of Sponges only differed clearly between methods at the shortest sampling 244 distance (i.e. $5 \mathrm{~m}$ ), IDW being more accurate (Fig 5). 

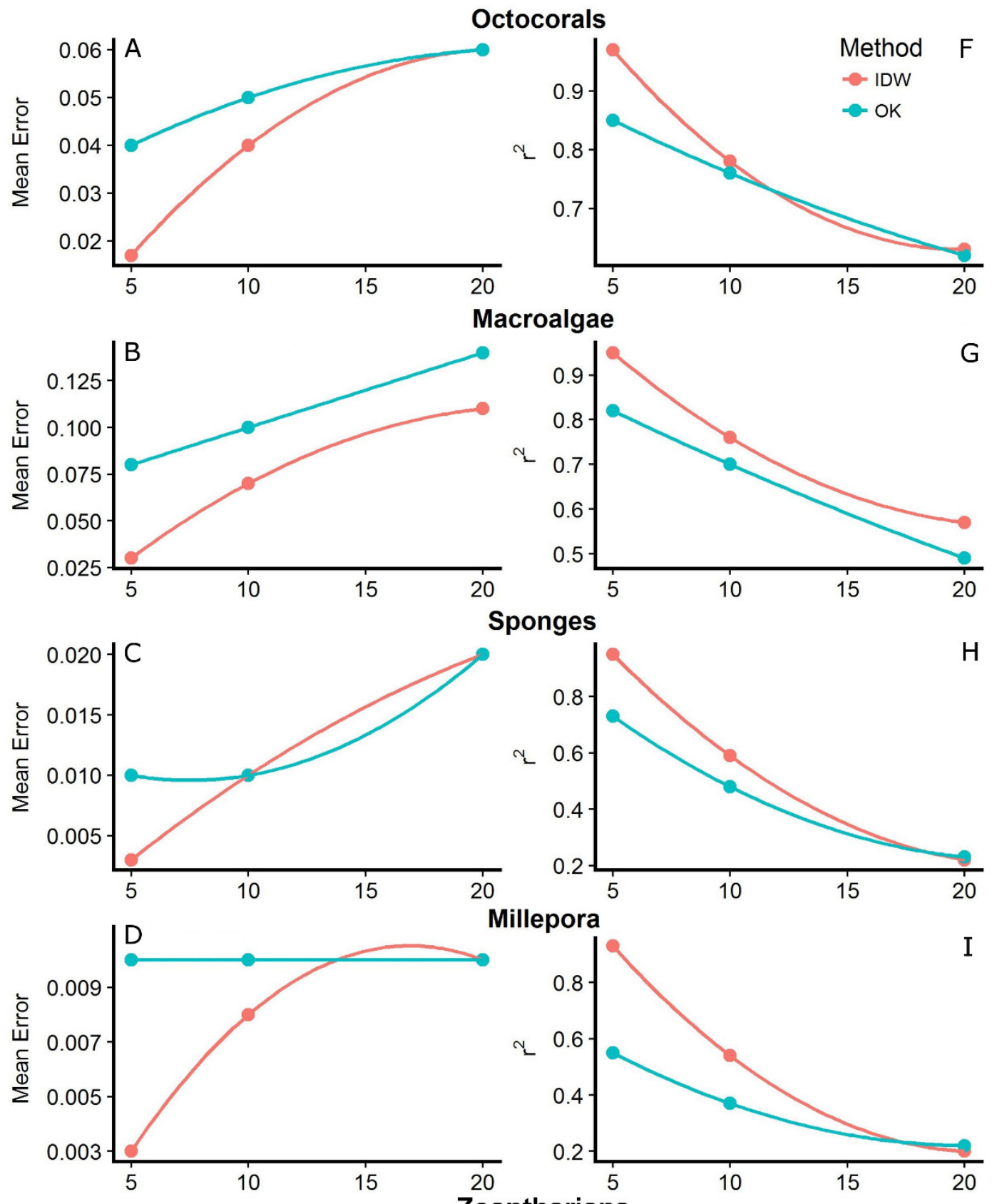

Millepora

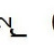
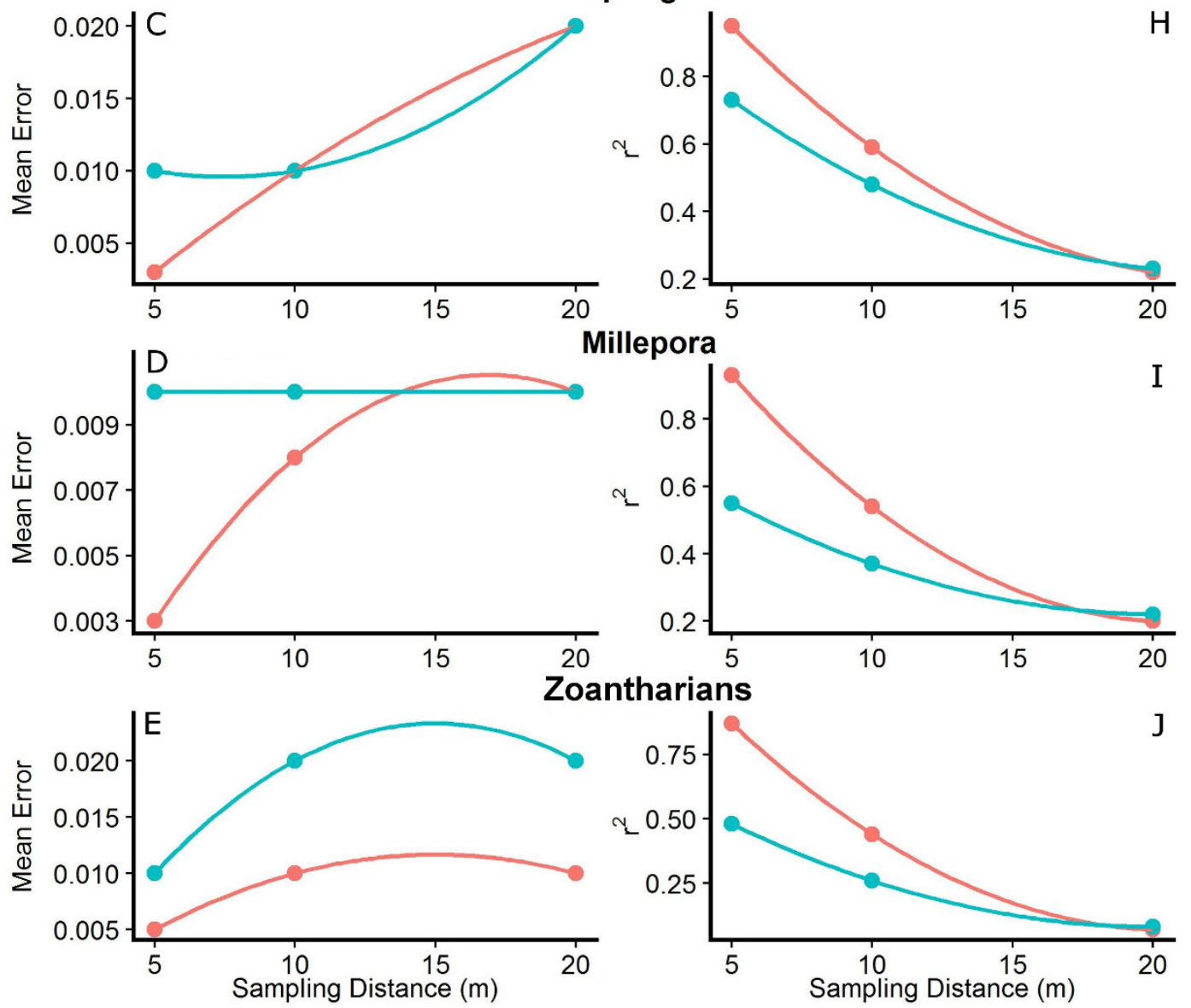

Figure 5. Mean errors of the predictions (A-E) and correlation coefficients $\left(\mathrm{r}^{2}, \mathrm{~F}-\mathrm{J}\right)$ between measured

248 and predicted values of the interpolations from Inverse Distance Weighting (IDW) and Ordinary Kriging 
249 (OK) using datasets with different sampling distances $(5,10$ and $20 \mathrm{~m})$ of the abundance of macroalgae,

250 octocorals, sponges, zoantharians and Millepora alcicornis (millepora) at Madagascar reef, Gulf of

251 Mexico.

252 The distributions of the interpolated data of IDW at the shortest sampling distance, the highest

253 accuracy, had a higher resemblance to the measured values than those generated with OK for 254 each HFO (Fig. 6). IDW was a good predictor of the highest values of abundance measured in 255 situ for all HFO, whereas the predictions of OK fell short on octocorals, sponges, zoanthids and 256 M. alcicornis (Fig. 6).

257

258

259

260

261

262

263

264

265

266

267

268

269

270

271

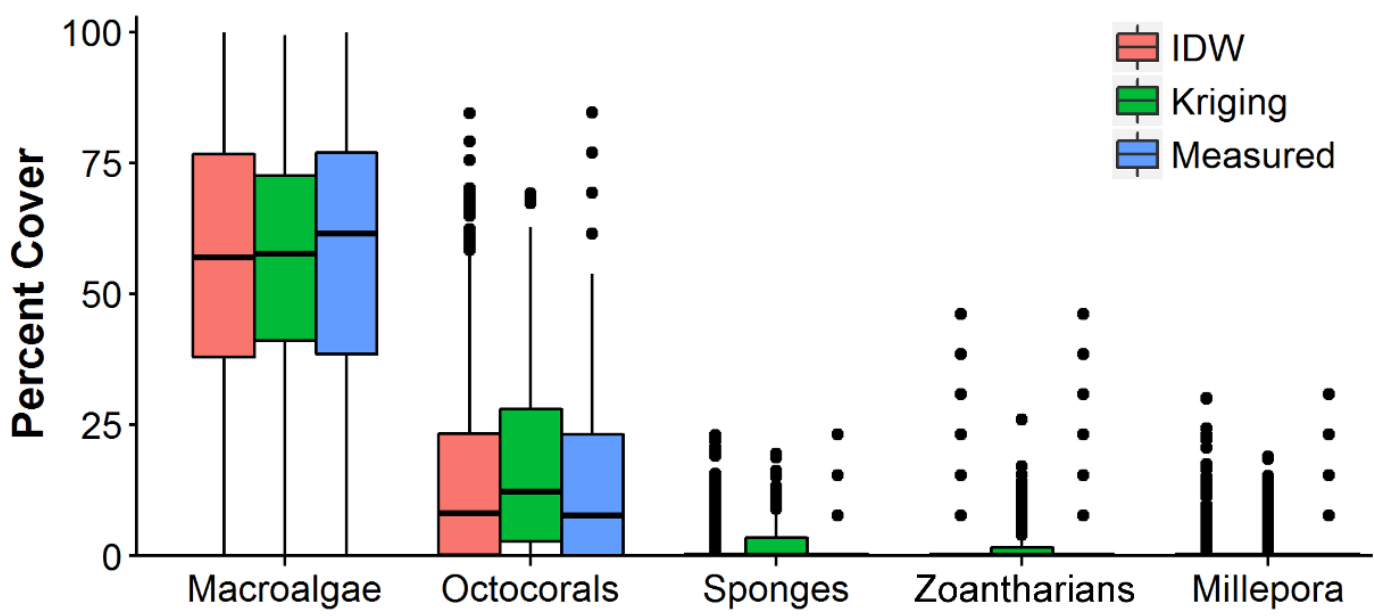

Figure 6. Comparison of the abundance values measured in situ of macroalgae, octocorals, sponges, zoantharians and Millepora alcicornis (millepora) of Madagascar reef, Gulf of Mexico, and those interpolated by Inverse Distance Weighting (IDW) and Ordinary Kriging during cross-validation. Box-plots represent four quartiles and median, with outliers as points.

The interpolation maps presented detailed information of the distribution and abundance of each HFO. The spatial distribution of all HFO was patchy, with specific areas of the reef presenting higher abundances. Macroalgae were distributed in all regions of the reef but were more abundant in deeper areas at the windward and leeward regions, where they covered up to $100 \%$ of the substrate (Fig. 7). Octocorals covered extensive areas of the reefscape as well, but patches at the central and western reef crest had higher abundances, where they covered up to $85 \%$ of the substrate (Fig. 7). Sponges were distributed all along the reef crest, presenting higher abundances $(25 \%)$ at the western side, with isolated colonies in deeper zones (Fig. 7). Zoantharians were present at the reef crest, where patches at the west and east sides covered up to $45 \%$ of the 
272 substrate; their distribution was interrupted at a region where macroalgae and octocorals had

273 high abundances (Fig. 7). M. alcicornis covered the smallest area of the reef among all the HFO;

274 colonies were distributed in three disconnected areas of the reef crest, at the western, centre and

275 eastern regions, each presenting patches covering up to $30 \%$ of the substrate (Fig. 7); the space

276 gaps between these areas of M. alcicornis had high abundances of other HFO (Fig. 7). 


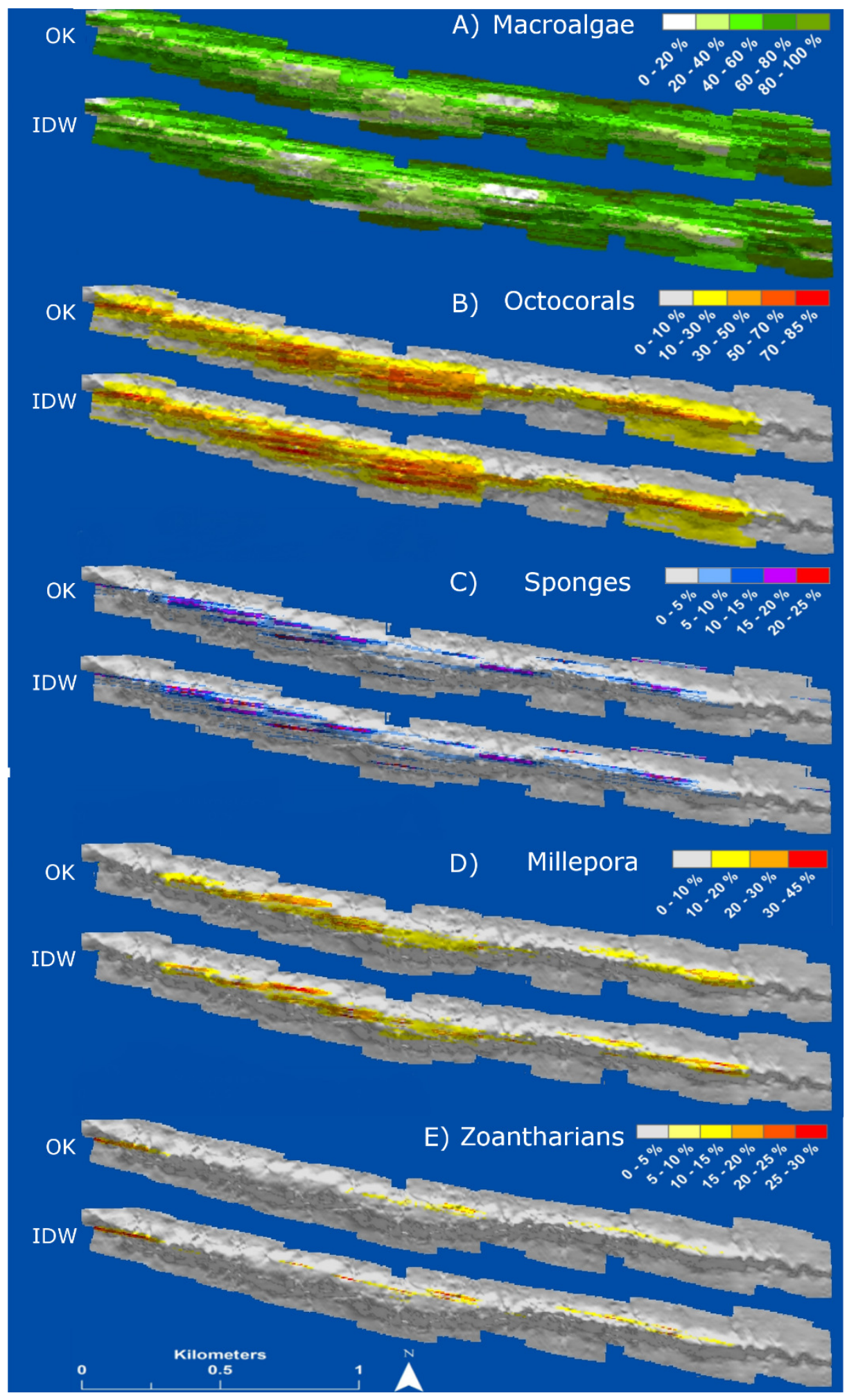

278 Figure 7. Maps of distribution and abundance (percent cover) generated by ordinary kriging (OK) and

279 inverse distance weighting (IDW) of the main groups of habitat-forming organisms of Madagascar reef,

280 Gulf of Mexico: macroalgae, octocorals, sponges, Millepora alcicornis (millepora) and zoantharians. 
282 HFO richness had a positive relationship with depth (Fig. 8). Deep sandy areas at the windward

283

284 and leeward regions had values of 1 , as only macroalgae were present at these areas; slightly shallower areas, where octocorals were more common, had values of 2 . Only the reef crest had extensive areas with values of 3 and 4 , where either M. alcicornis, sponges or zoantharians were present in addition to macroalgae and octocorals. Three areas with the highest richness levels were localized at the shallowest regions of the reef crest, one at the east and two on the west side (Fig. 8).

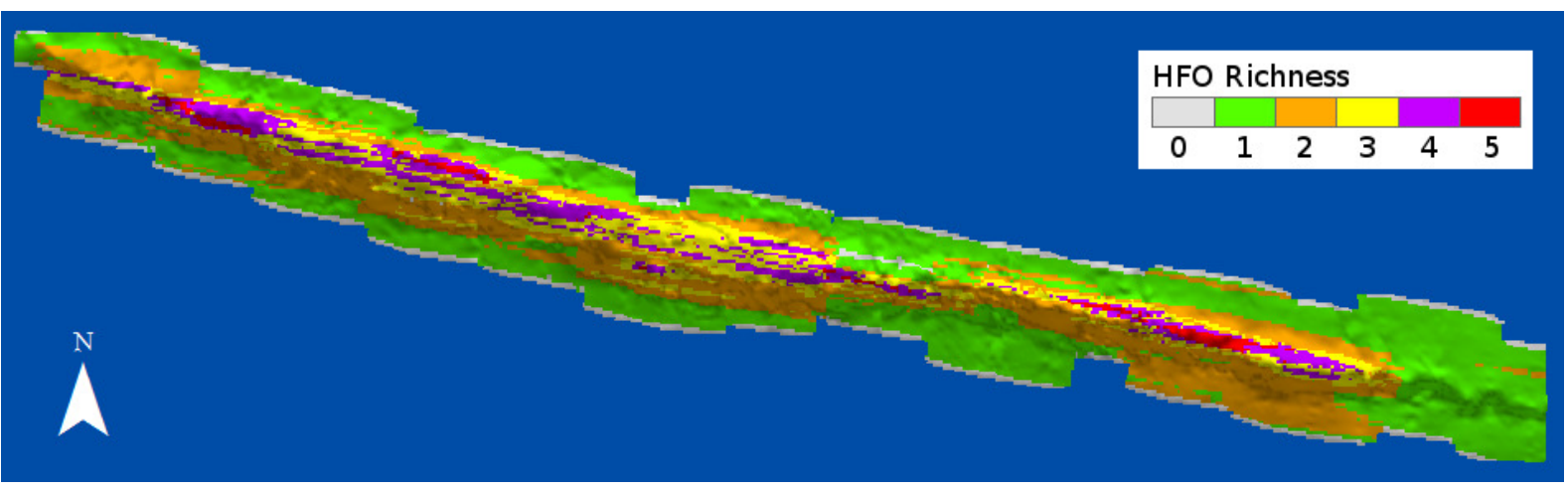

Figure 8. Richness of habitat-forming organisms (HFO) in Madagascar reef, Gulf of Mexico. The calculation considers the coexistence of macroalgae, octocorals, sponges, zoantharians and Millepora alcicornis.

\section{DISCUSSION}

Community structure

Madagascar reef sessile community differs from other reefs of the Gulf of Mexico. The windward and leeward regions of the reefs at the Campeche Bank Reef System, Veracruz Reef System and Tuxpan Reef System have been described as having important abundances of Scleractinian corals (Chávez, Tunnell \& Withers, 2007; Larson et al., 2014; Horta-Puga et al., 2015); however, at Madagascar reef, we found very small colonies and very low abundance of Scleractinian corals. Only the hard-coral M. alcicornis was conspicuous at the reef crest, while the leeward and windward regions were dominated by macroalgae. Our results also contrasted 
306

307

308

309

310

311

312

313

314

315

316

317

318

319

320

321

322

323

324

325

326

327

328

329

330

331

332

333

334

335

336

with reef systems further North, at the Flower Garden Banks, where surveys have reported high abundances of Scleractinian corals $(>50 \%)$ and low substrate cover $(<1 \%)$ of other sessile organisms, with the exception of Stetson Bank where high abundances of M. alcicornis (30\%) and sponges (30\%) have been registered (Hickerson et al., 2008).

Madagascar reef crest was dominated by octocorals and macroalgae, but sponges and zoantharians were very conspicuous in different patches of the reef. Studies in the Caribbean have reported abundances of sponges as high as $24 \%$ in shallow environments (Diaz \& Rützler, 2001), we found a lower average abundance at the reef crest (7\%); however, substrate cover reached $25 \%$ in some areas. Millepores usually cover $<10 \%$ of substrate over entire reefs but can be abundant in localized regions (Lewis, 2006), M. alcicornis covered $\sim 3 \%$ on average in Madagascar reef but in its more important areas of distribution its abundance reached $30 \%$. Zoantharians can have high abundances in shallow environments: reefs in Brazil had $~ 6 \%$ substrate covered on average (Silva et al., 2015) with 25\% in localized areas (Francini-Filho et al., 2013), in St. Croix reefs had 36\% cover (Suchanek \& Green, 1981) and intertidal flats of the Southern Caribbean can cover up to half of the substrate (Belford \& Phillip, 2012; Rabelo et al., 2015). Our data corresponded well with these prior studies, with zoantharians estimated to average $7.7 \%$ coverage and up to $45 \%$ coverage in core ranges.

Octocorals are a common element in reefs of the Gulf of Mexico, Caribbean (Jordan-Dahlgren, 2002) and other coral reefs of the world (Fabricius \& McCorry, 2006). However, octocoral abundance can vary widely across their habitat range. Studies in the Gulf of Mexico and Caribbean have reported low abundances (2\%) in Cuba (Chiappone et al., 2001), moderate abundances ( 16\%) in the Florida Keys (Ruzicka et al., 2013), and high abundances (54\%) across the Enmedio reef in Veracruz, Mexico (Nelson, Stinnett \& Tunnell, 1988). Studies of octocorals outside the Latinamerican region also report this variation, with some reefs at the Great Barrier Reef in Australia showing an average of 20\% cover (Fabricius, 1997), while high abundances have been reported in New Guinea (40\%) (Tursch \& Tursch, 1982) and the Red Sea (50\%) (Benayahu \& Loya, 1981). Octocoral abundance in Madagascar reef was similar to the highest values reported regionally and globally: $44 \%$ on average with $85 \%$ substrate covered on extensive areas of the reef crest. On the other hand, the high cover of macroalgae on all 
337 environments of the reef is not extraordinary given that this group has become dominant in many

338 coral reef regions of the world (Arias-Gonzalez et al., 2017).

339

340

Spatial interpolations

341

342 Literature points out that interpolation methods are affected distinctly by some factors, such as

343 the sampling distance or density of samples (Li \& Heap, 2008). Our results agreed with this; we

344 found that the accuracy of the interpolations was strongly affected by the distance between

345 samples, especially on the interpolations of HFO that were less abundant (i.e. sponges,

346 zoantharians and M. alcicornis). Interpolations based on sampling every $5 \mathrm{~m}$ were more accurate

347 in comparison with sampling distances of $10 \mathrm{~m}$ and $20 \mathrm{~m}$, which had $50 \%$ and $75 \%$ less

348 sampling units respectably. We must consider, however, that each study requires a specific

349 sample density, depending on the spatial variation of each phenomenon. If the variable of interest

350 presents changes at small scales, higher sampling density will be required, such as in our case,

351 but circumstances may arise where more spaced sampling would be appropriate (Li \& Heap,

352 2011).

353

354 Sampling density affected each interpolation methodology differently. At the sampling distance

355 of $5 \mathrm{~m}$ only IDW produced highly accurate interpolations for all HFO according to cross-

356 validations, making it a very promising methodology for the interpolation of the abundance of

357 sessile organisms inhabiting coral reefs. Although OK is generally considered a better

358 interpolator (Li et al., 2011), it only generated accurate maps of macroalgae and octocorals,

359 while the interpolations for M. alcicornis, sponges and zoantharians fell short of the highest

360 values measured in situ as shown in the cross-validations. Nonetheless, the OK interpolations

361 represented the distributions correctly and could allow the creation of presence/absence data,

362 which is a common expression of abundance in ecology (Royle \& Nichols, 2003). In contrast,

363 IDW did not underestimate the values gathered in situ and displayed lower mean errors and

364 higher $\mathrm{r}^{2}$ during cross-validations. Other studies have found similar results, where kriging is not

365 able to predict the highest values of the measured data (Hernandez-Flores et al., 2015) and IDW

366 outperforms kriging interpolators. Gong et al. (2014) found that IDW was the best interpolator

367 for arsenic concentrations in comparison with kriging, Spokas et al. (2003) concluded that IDW 
368

369

370

371

372

373

374

375

376

377

378

379

380

381

382

383

384

385

386

387

388

389

390

391

392

393

394

395

396

397

398

performed best for methane flux, and Wartenberg et al. (1991) pointed out that kriging was not superior to non-geostatistical methods at interpolating groundwater contamination despite its greater complexity.

The difference in performance between interpolation methods could be due to the variation of the data of each HFO. It has been found that variables with a high coefficient of variation $(\mathrm{CV})$ are prone to have higher errors when interpolated (Li \& Heap, 2011) and variables that have nonnormal distributions are problematic to interpolate accurately with kriging since the methodology assumes a normal distribution of the variable of interest (Hengl, 2007). This corresponds well with our results, since the abundance data of sponges, zoantharians and M. alcicornis, the HFO that $\mathrm{OK}$ failed to interpolate, had higher $\mathrm{CV}$ and had strongly skewed distributions in comparison to macroalgae and octocorals, which were interpolated accurately by OK. Interestingly, IDW didn't suffer in performance at the shortest sampling distance in our study regardless of the high $\mathrm{CV}$ of sponges, zoantharians and M. alcicornis.

\section{The importance of data spatialization}

Many ecological studies in the past have assessed the abundance of different HFO, but have not presented the information in a clear spatially explicit fashion (e.g. Newman et al., 2006; Ruzicka et al., 2013, but see Walker et al., 2012; Knudby et al., 2013; D’Antonio et al., 2016). This is an important aspect in modern ecology that should be a standard procedure in studies regarding community structure of marine ecosystems; we show that this can be done accurately for all HFO using a simple interpolation methodology. The interpolations allowed us to see the precise spatial patterns of distribution and abundance of each HFO. Non-spatial analyses summarize ecological data and give general trends of abundance through statistical graphics (e.g. boxplots); however, without geographic coordinates, these values do not describe the spatial patterns precisely, which may obscure inferences about macro-ecological processes. Our interpolations showed how the colonizable substrate of the reef was occupied by the HFO in a mosaic fashion. Each HFO had particular areas of high abundance values at the reef crest, suggesting that despite the general dominance of octocorals and macroalgae, there is ongoing strong competition for space. All the HFO are strong competitors (Wulff, 2006; Lewis, 2006; Rabelo, Soares \& 
399

400

401

402

403

404

405

406

407

408

409

410

411

412

413

414

415

416

417

418

419

420

421

422

423

424

425

426

427 428

Matthews-Cascon, 2013; Sebens \& Miles, 1988; Fong \& Paul, 2011; Cruz et al., 2016) and can influence the distribution and abundance of other groups by means of physical and chemical mechanisms that alter individual colonies and demographic processes of whole populations (Chadwik \& Morrow, 2011).

The higher HFO richness and competition among the sessile groups at the reef crest seems to be related to depth and substrate type. The rocky substrate of the reef crest allows the recruitment of individuals from all the HFO (Kinzie, 1973) and the expansion of established colonies through asexual reproduction (Jackson, 1977). In contrast, the sandy substrate of the windward and leeward regions is unstable and primarily favours the colonization of macroalgae, likely due to their high propagation capacities through spores, faster growth rates and substrate attachment through rhizoids which anchor the organism to the sand (Zakaria et al., 2006; Fong \& Paul, 2011). Larvae from other HFO might suffer high mortality rates due to sand smothering and abrasion, possibly enhanced by the high abundances of macroalgae (Chico et al., 2008). Additionally, the reef crest is associated with higher light irradiance and water movement that can benefit all HFO, since all groups have photosynthetic species and all invertebrate HFO are suspension feeders (Rützler, 1990; Lewis, 2006; Fabricius \& De'ath, 2008; Fong \& Paul 2011; Rabelo, Rocha \& Colares, 2014). However, octocorals are well known colonizers of turbulent environments due to their flexibility (Sánchez, Diaz \& Zea, 1997), and their branching morphologies can give them advantage to overshadow other HFO and feed on plankton under high water flows (Labarbera, 1984; Sebens, 1984; McFadden, 1986; Sebens \& Johnson, 1991; Fabricius, Genin \& Benayahu, 1995), which could explain their higher abundances at the reef crest. Madagascar reef receives waters from an upwelling in the eastern corner of the Yucatan Peninsula (Merino, 1997; Zavala-Hidalgo, 2006) which supplies the nutrients to support high abundances of plankton in the region (Ghinaglia, Herrera-Silveira \& Comin, 2004). High levels of nutrients can affect coral health (Vega et al., 2014) and species diversity (Duprey, Yasuhara \& Baker 2016), while facilitating the growth of other HFO (De'Ath \& Fabricius, 2010) and the establishment of sessile communities with low Scleractinian coral cover (Arias-Gonzalez et al., 2017), such as the trend we observed in Madagascar reef. 
429 Regions displaying the highest levels of HFO richness provide habitat heterogeneity that could 430 benefit many mobile species. Since each of the HFO provides unique habitats where different

431

432

433

434

435

436

437

438

439

440

441

442

443

444

445

446

447

448

449

450

451

452

453

454

455

456

457

458

459 species find refuge and food, these regions can be important centres of biodiversity in the ecosystem (Santavy et al., 2013). For instance, the lobster Panulirus argus (Marx \& Herrnkind, 1985; Herrnkind et al., 1997) and the grouper Epinephelus striatus (Dahlgren \& Eggleston, 2000) take refuge in sponges, octocorals and macroalgae during their juvenile stage. Many species of invertebrates (e.g. amphipods, copepods, mollusks, echinoderms and polychaetes) and fish inhabit the micro-habitats of macroalgae (Dulvy et al., 2002), octocorals (Goh, $\mathrm{Ng} \&$ Chou, 1999), sponges (Duffy, 1992; Wulff, 2006), zoantharians (Pérez, Vila-Nova \& Santos, 2005) and millepores (Lewis, 2006). Furthermore, HFO serve as food resources; Hawksbill turtles feed on sponges and macroalgae (Bjorndal, 1990) and several species of fish feed on zoantharians (Francini-filho \& Moura 2010), macroalgae (Choat, Clements \& Robbins, 2002) and sponges (Pawlik et al., 1995), while species of molluscs, echinoderms and crustaceans consume sponges as well (Wulff, 2006).

\section{CONCLUSION}

The generation of spatial information about the abundance of biological organisms is needed to establish monitoring programs, detect changes in the community over time and allow conservation planning for natural ecosystems. The comparison between IDW and OK, a popular but more complex and time-consuming methodology, allowed us to conclude that, in this case, simple is best. The only published past studies using IDW in coral reef sessile organisms found this method to be a good interpolator for coral cover (Walker et al., 2012; D'Antonio et al., 2016); our results corroborate these findings and we extend the applicability of this method to other important sessile organisms that are becoming more abundant, likely because of climate change (Norström et al., 2009). Importantly, the sampling design, sample density and location must be adequate to the spatial variation of the organisms of interest. We showed that Madagascar reef supported important abundances of all the HFO at the reef crest region, with high HFO richness in specific areas. The accurate spatial interpolations created using IDW allowed us to see the spatial variability of each HFO at a biological and spatial resolution that remote sensing would not have been able to produce. This study provides the basis for further 
460 biological research projects and conservation management in Madagascar reef and encourages

461 similar studies in the region and other parts of the world where remote sensing technologies are 462 not suitable for use.

463

464

\section{REFERENCES}

465

466

467

468

469

470

471

472

473

474

475

476

477

478

479

480

481

482

483

484

485

486

487

488

489

Andrefouet S, Kramer P, Torres-Pulliza D, Joyce KE, Hochberg EJ, Garza-Perez R, Mumby PJ, Riegl B, Yamano H, White WH, Zubia M, Brock JC, Phinn SR, Naseer A, Hatcher BG, Muller-Karger FE. 2003. Multi-site evaluation of IKONOS data for classification of tropical coral reef environments. Remote Sensing of Environment 88:128-143

Arias-González JE, Fung T, Seymour RM, Garza-Pérez JR, Acosta-González G, Bozec Y-M, et al. 2017. A coral-algal phase shift in Mesoamerica not driven by changes in herbivorous fish abundance. PLoS ONE 12: e0174855.

Belford SG \& Phillip DAT. 2012. Intertidal distribution patterns of zoanthids compared to their scleractinian counterparts in the southern Caribbean. International Journal of Oceanography and Marine Ecological System 1:67-75.

Bello-Pineda J, Hernández-Stefanoni JL. 2007. Comparing the performance of two spatial interpolation methods for creating a digital bathymetric model of the Yucatan submerged platform. Pan-American Journal of Aquatic Sciences 2: 247-254.

Bell JJ, Davy SK, Jones, T, Taylor MW, Webster NS. 2013. Could some coral reefs become sponge reefs as our climate changes? Global Change Biology 19: 2613-2624.

Benayahu Y, Loya Y. 1981. Competition for space among coral-reef sessile organisms at Eilat, Red Sea. Bulletin of Marine Science 31: 514-522.

Berry C, Hill RL, Walker BK. 2016. Demographics of a nearshore mating queen conch (Lobatus gigas) aggregation on the southeast Florida Reef Tract. Bulletin of Marine Science 92:59-73. Bjorndal KA. 1990. Digestibility of the sponge Chondrilla nucula in the green turtle, Chelonia mydas. Bulletin of Marine Science 47: 567-570.

Botha EJ, Brando VE, Anstee JM, Dekker AG, Sagar S. 2013. Increased spectral resolution enhances coral detection under varying water conditions. Remote Sensing of Environment 131: 247-261. 
490

491

492

493

494

495

496

497

498

499

500

501

502

503

504

505

506

507

508

509

510

511

512

513

514

515

516

517

518

519

Burman SG, Aronson RB, van Woesik R. 2012. Biotic homogenization of coral assemblages along the Florida reef tract. Marine Ecology Progress Series 467: 89-96.

Chadwik NE, Morrow K.M. 2011. Competition among sessile organisms on coral reefs. In: Dubinsky Z, Stambler N, eds. Coral Reefs: An ecosystem in transition. Netherlands Springer Verlag, 347-371.

Chávez EA, Tunnell Jr JW, Withers K. 2007. Zonación y ecología de los arrecifes: plataforma veracruzana y Banco de Campeche. In: Tunnell Jr JW, Chávez EA, Withers K, Earle S, eds. Coral Reefs of the Southern Gulf of Mexico. Texas A\&M University Press, 60-100.

Cházaro-Olivera S, Vázquez-López H. 2014. Association of Synalpheus (Crustacea, Decapoda, Alpheidae) with the sponges from Parque Marino Nacional Sistema Arrecifal Veracruzano, SW Gulf of Mexico. Biocyt 7: 465-473.

Chiappone M, Sullivan-Sealey K, Bustamante G, Tschirky J. 2001. A rapid assessment of coral reef community structure and diversity patterns at naval station Guantánamo Bay, Cuba. Bulletin of Marine Science 69: 373-394.

Choat JH, Clements KD, Robbins WD. 2002. The trophic status of herbivorous fishes on coral reefs I. Dietary analysis. Marine Biology 140: 613-623.

Cohen PJ, Foale SJ. 2013. Sustaining small-scale fisheries with periodically harvested marine reserves. Marine Policy 37: 278-287.

Cruz ICS, de Kikuchi RKP, Longo LL, Creed JC. 2014. Evidence of a phase shift to Epizoanthus gabrieli Carlgreen, 1951 (Order Zoanthidea) and loss of coral cover on reefs in the Southwest Atlantic. Marine Ecology 36: 318-325.

Dahlgren CP, Eggleston DB. 2000. Ecological processes underlying ontogenetic habitat shifts in a coral reef fish. Ecology 81: 2227-2240.

D'Antonio NL, Gilliam DS, Walker BK. 2016. Investigating the spatial distribution and effects of nearshore topography on Acropora cervicornis abundance in Southeast Florida. PeerJ 4:e2473

Diaz MC, Rützler K. 2001. Sponges: An essential component of Caribbean coral reefs. Bulletin of Marine Science 69: 535-546.

De'Ath G, Fabricius K. 2010. Water quality as a regional driver of coral biodiversity and macroalgae on the Great Barrier Reef. Ecological Applications 20: 840-850. 
520 De Mazières J, Comley J. 2008. An investigation of coral reef fish assemblage modelling with

521 geostatistical methods. Proceedings of the 11th International Coral Reef Symposium 1: 602522606 .

523 Duffy JE. 1992. Host use patterns and demography in a guild of tropical sponge-dwelling 524 shrimps. Marine Ecology Progress Series 90: 127-138.

525 Dulvy NK, Mitchell RE, Watson DJ, Sweeting CJ, Polunin NVC. 2002. Scale-dependent control 526 of motile epifaunal community structure along a coral reef fishing gradient. Journal of 527 Experimental Marine Biology and Ecology 278: 1-29.

528 Duprey NN, Yasuhara M, Baker DM. 2016. Reefs of tomorrow: eutrophication reduces coral 529 biodiversity in an urbanized seascape. Global Change Biology 22: 3550-3565.

530 Fabricius KE, Genin A, Benayahu Y. 1995. Flow-dependent herbivory and growth in 531 zooxanthellae-free soft corals. Limnology and Oceanography 40: 1290-1301.

532 Fabricius KE. 1997. Soft coral abundance on the central Great Barrier Reef: effects of 533 Acanthaster planci, space availability, and aspects of the physical environment. Coral Reefs $534 \quad 16: 159-167$.

535 Fabricius KE, McCorry D. 2006. Changes in octocoral communities and benthic cover along a 536 water quality gradient in the reefs of Hong Kong. Marine Pollution Bulletin. 52: 22-33.

537 Fabricius KE, De'ath G. 2008. Photosynthetic symbionts and energy supply determine octocoral 538 biodiversity in coral reefs. Ecology 89:3163-3173

539 Fong P, Paul VJ. 2011. Coral reef algae. In: Dubinsky Z, Stambler N, eds. Coral Reefs: An 540 ecosystem in transition. Netherlands Springer Verlag, 241-272.

541 Francini-Filho RB, Moura RL. 2010. Predation on the toxic zoanthid Palythoa caribeorum by 542 reef fishes in the Abrolhos Bank, eastern Brazil. Brazilian Journal of Oceanography 58: 7754379.

544 Francini-Filho RB, Coni ECO, Meirelles PM, Amado-Filho GM, Thompson FL, Pereira-Filho 545 GH, Bastos AC, Abrantes DP, Ferreira CM, Gibran FZ, Guth AZ, Sumida PYG, Oliveira NL, 546 Kaufman L, Minte-Vera CM, Moura RL. 2013. Dynamics of coral reef benthic assemblages 547 of the Abrolhos Bank, Eastern Brazil: inferences on natural and anthropogenic drivers. PLoS 548 ONE 8: e54260. 
549 Franklin EC, Ault JS, Smith SG, Luo J, Meester GA, Diaz GA, Chiappone M, Swanson DW, 550 Miller SL, Bohnsack JA. 2003. Benthic habitat mapping in the Tortugas Region, Florida. 551 Marine Geodesy 26: 19-34. Doi: 10.1080/01490410306706.

552 Ghinaglia LT, Herrera-Silveira JA, Comin FA. 2004. Structural variations of phytoplankton in 553 the coastal seas of Yucatan, Mexico. Hydrobiologia 519: 85-102.

554 Goh NKC, Ng PKL, Chou LM. 1999. Notes on the shallow water gorgonian-associated fauna on 555 coral reefs in Singapore. Bulletin of Marine Science 65: 259-282.

556 Gong G, Mattevada S, O’Bryant SE. 2014. Comparison of the accuracy of kriging and IDW 557 interpolations in estimating groundwater arsenic concentrations in Texas. Environmental 558 Research 130: 59-69.

559 Goovaerts P. 1997. Geostatistics for Natural Resource Evaluation. Oxford University Press. 560 Gross M. 2013. Hopes and fears for future of coral reefs. Current Biology, 23: 635-637.

561 Heng T. 2007. A practical guide to geostatistical mapping of environmental variables. Office for 562 Official Publication of the European Communities, Luxembourg.

563 Hernandez-Flores A, Condal A, Poot-Salazar A, Espinoza-Mendez JC. 2015. Fisheries Research. 564 Geostatistical analysis and spatial modeling of population density for the sea cucumbers 565 Isostichopus badionotus and Holothuria floriana on the Yucatan Peninsula, Mexico. Fisheries $566 \quad$ Research 172: 114-124.

567 Herrnkind WF, Butler IV MJ, Hunt JH, Childress M. 1997. Role of physical refugia:

568 implications from a mass sponge die-off in a lobster nursery in Florida. Marine and 569 Freshwater Research 48: 759-770.

570 Hickerson EL, Schmahl GP, Robbart M, Precht WF, Caldow C. 2008. The state of the coral reef 571 ecosystems of the Flower Garden Banks, Stetson Bank and other banks in the northwestern 572 Gulf of Mexico. In: The state of coral reef ecosystems of the United States and Pacific Freely 573 Associated States: 2008. NOAA Technical Memorandum NOS NCCOS 73. NOAA/NCCOS

574 Center for Coastal Monitoring and Assessment's Biogeography Team. Silver Spring, MD. $575 \quad 569 \mathrm{pp}$.

576 Hochberg EJ, Atkinson MJ. 2003. Capabilities of remote sensors to classify coral, algae, and 577 sand as pure and mixed spectra. Remote Sensing of Environment 85: 174-189. 
578 Holmes KW, Van Niel KP, Kendrick GA, Radford B. 2007. Probabilistic large-area mapping of 579 seagrass species distributions. Aquatic Conservation: Marine and Freshwater Ecosystems 17: $580 \quad 385-407$.

581 Horta-Puga GJL, Tello-Musi A, Beltrán-Torres JP, Carricart-Ganivet JD, Carriquiry J,

582 Villaescusa-Celaya J. 2015. Veracruz Reef System: a hermatypic coral community thriving in 583 a sedimentary terrigenous environment. In: Granados-Barba A, Ortiz-Lozano L, Salas-

584 Monreal D, González-Gándara C, eds. Aportes al conocimiento del Sistema Arrecifal

585 Veracruzano: Hacia el Corredor Arrecifal del Suroeste del Golfo de México. Universidad 586 Autonoma de Campeche, 181-207.

587 Jackson, JBC. 1977. Competition on marine hard substrata: The adaptive significance of solitary 588 and colonial strategies. The American Naturalist, 111: 743-767.

Jordan-Dahlgren. 2002. Gorgonian distribution patterns in coral reef environments of the Gulf of 590 Mexico: Evidence of sporadic ecological connectivity? Coral Reefs. 21: 205-215.

Kachelriess D, Wegmann M, Gollock M, Pettorelli N. 2014 The application of remote sensing 593 594

Kinzie RA. 1973. The zonation of West Indian gorgonians. Bulletin of Marine Science 231: 559-

$$
592 .
$$

Knudby A, Jupiter S, Roelfsema C, Lyons M, Phinn S. 2013. Mapping coral reef resilience indicators using field and remotely sensed data. Remote Sensing 5: 1311-1334.

Kutser T, Jupp DLB. 2006. On the possibility of mapping living corals to the species level based on their optical signatures. Estuarine, Coastal and Shelf Science 69:607-614.

Labarbera M. 1984. Feeding currents and particle capture mechanisms in suspension feeding animals. Integrative \& Comparative Biology 24: 71-84.

Larson EA, Gilliam DS, Lopez-Padierna GM, Walker BK. 2014. Possible recovery of Acropora palmata (Scleractinia:Acroporidae) within the Veracruz Reef System, Gulf of Mexico: a survey of 24 reefs to assess the benthic communities. Revista de Biología Tropical 62: 75-84. Lee ST, Kelly M, Langlois TJ, Costello MJ. 2015. Baseline seabed habitat and biotope mapping for a proposed marine reserve. PeerJ 3: e1446.

Lewis JB. 2006 Biology and ecology of the hydrocoral Millepora on coral reefs. Advances in Marine Biology 50: 1-55. 
608 Li J, Heap AD. 2008. A review of spatial interpolation methods for environmental scientists.

609 Canberra, Geoscience Australia Record 2008/23.

610 Li J, Heap AD. 2011. A review of comparative studies of spatial interpolation methods in

611 environmental sciences: Performance and impact factors. Ecological Informatics 6: 228-241.

612 Li J, Heap AD, Potter A, Huang Z, Daniell JJ. 2011. Can we improve the spatial predictions of

613 seabed sediments? A case study of spatial interpolation of mud content across the southwest

614 Australian margin. Continental Shelf Research 31: 1365-1376.

615 Li J, Heap AD. 2014. Spatial interpolation methods applied in the environmental sciences: A

616 review. Environmental Modelling \& Software 53: 173-189.

617 Lucas MQ, Goodman J. 2014. Linking coral reef remote sensing and field ecology: it's a matter

618 of scale. Journal of Marine Science and Engineering 3: 1-20.

619 Marx JM, Herrnkind WF. 1985. Macroalgae (Rhodophyta: Laurencia spp.) as a habitat for young

620 juvenile spiny lobsters, Panulirus argus. Bulletin of Marine Science 36: 423-431.

621 McClanahan TR, Maina JM, Muthiga NA. 2011. Associations between climate stress and coral

622 reef diversity in the Western Indian Ocean. Global Change Biology 17: 2023-2032.

623 McFadden CS. 1986. Colony fission increases particle capture rates of a soft coral: advantages of

624 being a small colony. Journal of Experimental Marine Biology and Ecology 103: 1-20

625 McManus JW, Polsenberg JF. 2004. Coral-algal phase shifts on coral reefs: ecological and

626 environmental aspects. Progress in Oceanography 60: 263-279.

627 McMurray SE, Finelli CM, Pawlik JR. 2015. Population dynamics of giant barrel sponges on

628 Florida coral reefs. Journal of Experimental Marine Biology and Ecology. 473: 73-80.

629 Merino M. 1997. Upwelling on the Yucatan Shelf: hydrographic evidence. Journal of Marine

630 Systems 13:101-121.

631 Miller JR, Turner MG, Smithwick EAH, Dent CL, Stanley EH. 2004. Spatial extrapolation: the

632 science of predicting ecological patterns and processes. BioScience 54: 310-320.

633 Moberg F, Folke C. 1999. Ecological goods and services of coral reef ecosystems. Ecology

634 Economics 29: 215-233.

635 Mueller TG, Pusuluri NB, Mathias KK, Cornelius PL, Barnhisel RI, Shearer SA.

636 2004. Map quality for Ordinary Kriging and Inverse Distance Weighted interpolation. Soil

637 Science Society of America Journal 68: 2042-2047 
638 Mumby PJ, Elliott IA, Eakin CM, Skirving W, Paris CB, Edwards HJ, Enriquez S, Iglesias-

639 Prieto R, Cherubin LM, Stevens JR. 2011. Reserve design for uncertain responses of coral 640 reefs to climate change. Ecology Letters 14: 132-140.

641 Nelson TJ, Stinnett TL, Tunnell JW. 1988. Quantitative assessment of an unusually dense 642 octocoral community in the southwestern Gulf of Mexico. Proceedings of the 6th 643 International Coral Reef Symposium, 2: 791-796.

644 Newman MJ, Paredes GA, Sala E, Jackson JB. 2006. Structure of Caribbean coral reef 645 communities across a large gradient of fish biomass. Ecology letters 9: 1216-1227.

646 Norström AV, Norström M, Lokrantz J, Folke C. 2009. Alternative states on coral reefs: beyond 647 coral-macroalgal phase shifts. Marine Ecology Progress Series 376: 295-306.

648 Nyström M, Folke C, Moberg F. 2000. Coral reef disturbance and resilience in a human 649 dominated environment. Trends in Ecology and Evolution 15: 413-417.

650 Nyström M, Folke C. 2001. Spatial resilience of coral reefs. Ecosystems 4: 406-417. 651 doi:10.1007/s10021-001-0019-y

652 Pawlik JR, Chanas B, Toonen RJ, Fenical W. 1995. Defenses of Caribbean sponges against 653 predatory reef fish. I. Chemical deterrency. Marine Ecology Progress Series 127: 183-194.

654 Pérez CD, Vila-Nova DA, Santos AM. 2005. Associated community with the zoanthid Palythoa 655 caribeorum (Duchassaing \& Michelotti, 1860) (Cnidaria, Anthozoa) from littoral 656 Pernambuco, Brazil. Hydrobiologia 548: 207-215.

657 Plaisance L, Caley MJ, Brainard RE, Knowlton N. 2011. The diversity of coral reefs: what are 658 we missing? PLOS ONE 6: e25026. doi: 10.1371/journal.pone.0025026.

659 Rabelo EF, Soares MO, Matthews-Cascon H. 2013. Competitive interactions among zoanthids 660 (Cnidaria: Zoanthidae) in an intertidal zone of Northeastern Brazil. Brazilian Journal of 661 Oceanography 61: 35-42.

662 Rabelo EF, Rocha LL, Colares GB, Bomfim TA, Rodriges-Nogueira VL, Katzenberger M, 663 Matthews-Cascon H, Maciel-Melo VM. 2014. Symbiodinium diversity associated with 664 zoanthids (Cnidaria: Hexacorallia) in Northeastern Brazil. Symbiosis 64: 105-113.

665 Rabelo EF, Soares MO, Bezerra LEA, Matthews-Cascon H. 2015. Distribution pattern of 666 zoanthids (Cnidaria: Zoantharia) on a tropical reef. Marine Biology Research 11: 584-592. 
667 Royle JA, Nichols JD. 2003. Estimating abundance from repeated presence-absence data or 668 point counts. Ecology 84: 777-790.

669 Rueda M, Defeo O. 2003. Spatial structure of fish assemblages in a tropical estuarine lagoon: 670 combining multivariate and geostatistical techniques. Journal of Experimental Marine 671 Biology and Ecology 296: 93-112.

672 Rufino MM, Maynou F, Abelló P, Gil de Sola L, Yule AB. 2005. The effect of methodological 673 options of geostatistical modelling of animal distribution: A case study with Liocarcinus 674 depurator (Crustacea: Brachyura) trawl survey data. Fisheries Research 76, 252-265.

675 Ruppert JL, Fortin MJ, Rose GA, Devillers R. 2009. Atlantic cod (Gadus morhua) distribution 676 response to environmental variability in the northern Gulf of St. Lawrence. Canadian Journal 677 of Fisheries and Aquatic Science 66: 909-918.

678 Rützler K. 1990. Associations between Caribbean sponges and photosynthetic organisms. In:

679 Rützler K, ed. New perspectives in sponge biology. Washington, D.C.: Smithsonian Institution 680 Press, $455-466$.

681 Ruzicka RR, Colella MA, Porter JW, Morrison JM, Kidney JA, Brinkhuis V, Lunz KS, 682 Macaulay KA, Bartlett LA, Meyers MK, Colee J. 2013. Temporal changes in benthic 683 assemblages on Florida Keys reefs 11 years after the 1997/1998 El Niño. Marine Ecology 684 Progress Series 489: 125-141.

685 Sánchez JA, Díaz JM, Zea S. 1997. Gorgonian communities in two contrasting environments on 686 oceanic atolls of the southwestern Caribbean. Bulletin of Marine Science 61: 453-465.

687 Santavy DL, Courtney LA, Fisher WS, Quarles RL, Jordan SJ. 2013. Estimating surface area of 688 sponges and gorgonians as indicators of habitat availability on Caribbean coral reefs. 689 Hydrobiologia 707: 1-16.

690 Sebens K. 1984. Water flow and coral colony size: Interhabitat comparisons of the octocoral 691 Alcyonium siderium. Proceedings of the National Academy of Sciences 81: 5473-5477. 692 Sebens KP, Miles JS. 1988. Sweeper tentacles in a gorgonian octocoral: morphological 693 modification for interference competition. Biological Bulletin 175: 378-387.

694 Sebens, K.P. \& Johnson, A.S. 1991. Effects of water movement on prey capture and distribution 695 of reef corals. Hydrobiologia 226: 91-101. 
696 Silva JF, Gomes PB, Santana EC, Silva JM, Lima EP, Santos AMM, Pérez CD. 2015. Growth of 697 the tropical zoanthid Palythoa caribaeorum (Cnidaria: Anthozoa) on reefs in northeastern 698 Brazil. Annals of the Brazilian Academy of Sciences 87: 985-996.

699 Spokas K, Graff C, Morcet M, Aran C. 2003. Implications of the spatial variability of landfill 700 emission rates on geospatial analyses. Waste Management 23: 599-607.

701 Suchanek TH, Green DJ. 1981. Interspecific competition between Palythoa caribaeorum and 702 other sessile invertebrates on St. Croix reefs, U. S. Virgin Islands. Proceedings of the Fourth 703 International Coral Reef Symposium 2: 679-684.

704 Surette TJ, Marcotte D, Wade E. 2007. Predicting snow crab (Chionoecetes opilio) abundance 705 using kriging with external drift and depth as a covariate. Canadian Technical Report of 706 Fisheries and Aquatic Sciences 2763. Fisheries and Oceans Canada.

707 Tursch B, Tursch A. 1982. The soft coral community on a sheltered reef quadrat at Laing Island 708 (Papua New Guinea). Marine Biology 68: 321-332.

709 Vega Thurber RL, Burkepile DE, Fuchs C, Shantz AA, McMinds R, Zaneveld JR. 2014. Chronic 710 nutrient enrichment increases prevalence and severity of coral disease and bleaching. Global 711 Change Biology 20: 544-554.

712 Walker BK, Larson EA, Moulding AL, Gilliam DS. 2012. Small-scale mapping of indeterminate 713 arborescent acroporid coral (Acropora cervicornis) patches. Coral Reefs 31:885-894.

714 Wartenberg D, Uchrin C, Coogan P. 1991. Estimating exposure using kriging: a simulation 715 study. Environmental Health Perspectives 94: 75-82.

716 Wilkinson CR. 2004. Status of Coral reefs of the World: 2004. Global Coral Reef Monitoring 717 Network, Australian Institute of Marine Science.

718 Wee HB, Reimer JD, Safuan M, Saidin J, Tan CH, Bachok Z. 2017. Zoantharian abundance in 719 coral reef benthic communities at Terengganu Islands, Malaysia. Regional Studies in Marine 720 Science 12: 58-63.

721 Wulff JL. 2006. Ecological interactions of marine sponges. Canadian Journal of Zoology $72284: 146-166$.

723 Zakaria MH, Bujang JS, Amit R, Awing SA, Ogawa H. 2006. Marine macrophytes: Macroalgae 724 species and life forms from Golden Beach, Similajau National Park, Bintulu, Malaysia. 725 Coastal Marine Science 30: 243-246. 
726 Zapata-Ramírez PA, Blanchon P, Olioso A, Hernandez-Nuñez H, Sobrino J.A. 2013. Accuracy

727 of IKONOS for mapping benthic coral-reef habitats: a case study from the Puerto Morelos

728 Reef National Park, Mexico. International Journal of Remote Sensing, 34: 3671-3687, Doi:

$729 \quad 10.1080 / 01431161.2012 .716922$.

730 Zarco-Perello S, Mascaró M, Garza-Pérez R, Simoes N. 2013. Topography and coral community

731 of the Sisal Reefs, Campeche Bank, Yucatán, México. Hidrobiológica 23: 28-41.

732 Zarco-Perello S, Moreno-Mendoza R, Simões N. 2014. Checklist of fishes from Madagascar

733 reef, Campeche Bank, México. Biodiversity Data Journal 2: e1100. doi:

$734 \quad 10.3897 / B D J .2 . e 1100$

735 Zavala-Hidalgo J, Gallegos-García A, Martínez-López B, Morey SL, O’Brien JJ. 2006. Seasonal

736 upwelling on the Western and Southern Shelves of the Gulf of Mexico. Ocean Dynamics 56:

$737 \quad 333-338$.

738

739 